\title{
Organochlorine Pesticides Residues in Water and Sediment from Rusinga Island, Lake Victoria, Kenya
}

\author{
Osoro $\mathrm{EM}^{1}$, Wandiga $\mathrm{SO}^{2}$, Abongo $\mathrm{DA}^{2}$, Madadi $\mathrm{V} \mathrm{O}^{2}$ and Macharia $\mathrm{J} \mathrm{W}^{2}$. \\ ${ }^{1}$ College of Biological and Physical Sciences, School of Physical Science, Department of Chemistry, University \\ of Nairobi, P.O. Box 30197-00100, Nairobi, Kenya. \\ ${ }^{2}$ College of Biological and Physical Sciences, School of Physical Science, Department of Chemistry, University \\ of Nairobi, P.O. Box 30197-00100, Nairobi, Kenya.
}

\begin{abstract}
This study was carried out to investigate the organochlorine pesticide residue level in representative sites in Rusinga Island of Lake Victoria, Kenya. Sediment and water samples from five sites along the shores of Rusinga Island in Lake Victoria were collected and analysed for selected organochlorine pesticides (OCP) using gas chromatography equipped with electron capture detector and confirmed using GC/MS. The pesticides targeted were p, $p^{\prime}-D D T, \gamma-H C H, \alpha-H C H, \beta-H C H, \delta-H C H$, aldrin, dieldrin, heptachlor, heptachlor epoxide, $p, p^{\prime}-D D E, p, p^{\prime}-D D D$, endrin, endrin, aldehyde, endosulfan sulfate, methoxychlor and endosulfan. The samples were collected seasonally between the months of September 2012 to May 2013. The residue levels of organochlorine pesticides in water samples during dry season ranged between BDL to $9.84 \pm 1.20 \mu \mathrm{g} / \mathrm{L}$. The levels in wet season ranged between below detection limit $(B D L)$ to $15.53 \pm 0.20 \mu \mathrm{g} / \mathrm{L}$. Organochlorine pesticide detected in sediment during dry season ranged between $B D L$ to $32.91 \pm 3.84$. Wet season the levels ranged between below detection limit (BDL) to $24.84 \pm 2.65 \mu \mathrm{g} / \mathrm{Kg}$.

The present result shows that organochlorines pesticides are still detected in our environment which can negatively affect our environment. This study provides baseline data on the levels of OCP residues in sediment and water from Lake Victoria. This will inform policy makers on the quality of water of Lake Victoria Basin as well as supplement the country's studies as an obligation for all parties to the Stockholm Convention on POPs.
\end{abstract}

Keywords: Lake Victoria,Organochlorine pesticide residues, Rusinga Island, , sediment and water pollution.

\section{Introduction}

There has been increasing trend in the use of pesticides in farming and public health vector control in Kenya due to the rapidly growing population and demand for food and agro-industrial products. Extensive use of pesticides has increased food production in many countries, however this has led to accumulation of pesticides residues in the environment, which pose threat to non target organism such as human, wildlife and invertebrates that can compromise ecosystem sustainability [1,2]. About 8,749 tones of different types of pesticides were imported into the country in 2006 of which $28 \%$ was insecticides and acaricides, 22\% herbicides, $36 \%$ fungicides and $14 \%$ other pesticides [3].

The international community came together in 2002 and approved the Stockholm Convention on Persistent Organic Pollutants (POPs) which was adopted on $22^{\text {nd }}$ May 2001 and started its work on $17^{\text {th }}$ May 2004. The main purpose of the Convention is to safeguard health and the environment from the toxic effect of POPs by reducing or eliminating their discharge to the environment. Kenya is a member of Stockholm Convention on POPs, which it signed on $24^{\text {th }}$ September, 2004. Twenty two chemicals are listed as POPs under the Stockholm Convention [4].

Persistent organic pollutants (POPs) are chemical compounds that have some physical and chemical characteristics which make them non degradable in the environment [5]. POPs accumulate in the fatty tissues of living organism including human and are found at higher concentration at higher levels in the food chain and are toxic to both human and wildlife. They are semi-volatile and as a result they are distributed through the cycle of volatilization and deposition known as the grass-hopper effect to regions where they have never been used or produced [6].

Recently Lake Victoria has undergone substantial environmental degradation from a range of human activities including unlawful fishing practices, contamination from human and industrial wastes, siltation from the erosion of deforested watersheds and urban runoff. There are many sources of contamination including, raw sewage, discharge of human and animal into lake and rivers, marine transport waste and pollution of lake water by human activities on the shores line. The growing impact of these activities are now evident with Lake Victoria showing various signs of severe environmental distress, including low oxygen concentration, eutrophication and reduced transparency and high levels of microbiological and chemical pollution [7]. Report show that Pesticides are used for killing bird pests [8] and in fishing [9]. In May 1999, press reports indicated 
that fishing in Lake Victoria was done using endosulfan pesticide. This resulted in the European Union imposing a fish import ban on all fish from Lake Victoria. Hence the economy of Kenya was affected as a result and estimated loss was more than US\$ 300 million.

Organochlorine pesticides which have now been banned in most of the developed countries are still illegally used or used for public health vector control in the East Africa region, hence their residues are finding their way into the lake waters [10].There is increase concern on the effects of human health and environment of organochlorine pesticides including birth defects and reproductive failure [11] endocrine disruption, immune system dysfunction and cancer [12, 13 and 14]. Long-term exposure to organochlorine pesticides has been implicated to kidney and liver dysfunctions, learning and behavioral problems (especially among children), premature and still births, nervous disorders and mutation $[15,16]$. There is some evidence indicating that organochlorine pesticides may also cause cancer in humans [13, 14].

Studies in Tanzania [17] and surveys [18] indicated use of organochlorine pesticides for agriculture and vector control programs and presence of their stockpiles within the riparian zone of lake Victoria. Some studies have reported organochlorine in water and sediments of Lake Victoria Uganda [19], also their presence in fish species from Lake Victoria Kenya [20]. Studies have shown high levels of organochlorine pesticides in water, soil and sediments in Nyando River tributary of the Kenyan's Lake Victoria [21, 22]. Also some studies indicate the presence of organochlorine pesticides in Kunywa River which passes through the Nzoia sugar company and drains its water to River Nzoia and then to Lake Victoria [23]. In Kenya most pesticide pollution cases go undetected, unreported and unanalyzed. It has been argued that poor land-use management practices, use of agrochemicals and the free movement of sediments and nutrients have impacts negatively on Lake Victoria ecosystem. It is therefore essential to monitor the residue levels organochlorine pesticide in Rusinga Island. The findings above contribute a springboard for our study on the Rusinga Island as part of a continuing approach to conserve environment of Lake Victoria basin. The aim of this study was to investigate residue levels of some selected organochlorine pesticides in Rusinga Island catchment area and know the pesticide residue levels in sediment and water samples.

\section{Materials And Methods}

\section{Study Area}

Rusinga Island lies on the $\left(0^{\circ} 35^{\prime}-0^{\circ} 44^{\prime} \mathrm{S}\right.$ and; $\left.34^{\circ} 11^{\prime}-34^{\circ} 22^{\prime} \mathrm{E}\right)$, and an altitude of $1,100 \mathrm{~m}$ with an area of $42 \mathrm{~km}^{2}$. The island is linked to the main land at Mbita town through a causeway that was constructed in 1983. The island is approximately $16 \mathrm{~km}$ from one end to another and $5 \mathrm{~km}$ at its widest end, it lies at the entrance of Winam Gulf in Kenya [24]. The Rusinga channel is a region of active exchange involving the gulf and the main lake. Several rivers with yearly discharge of $2.4 \mathrm{~km}^{3}$ flow into the Winam Gulf, draining rich intensive farming areas, municipalities and manufacturing areas all of which supply heavy loads of suspended sediments and nutrients into the gulf [24]. For that reason, the water in Winam Gulf is considered eutrophic based on chlorophyll data, total phosphorus and Secchi disc readings [10].

\section{Sampling Plan and Sites}

The samples were collected from 5 sampling sites in Rusinga Island in Lake Victoria Figure 1. The sampling was done four times in different seasons i.e. in September and December (2012), March and May (2013). This coincided with the effects of different seasons on pesticides residue levels covering the short dry (September), short rain (December), Long rain (May) and dry (March) seasons.

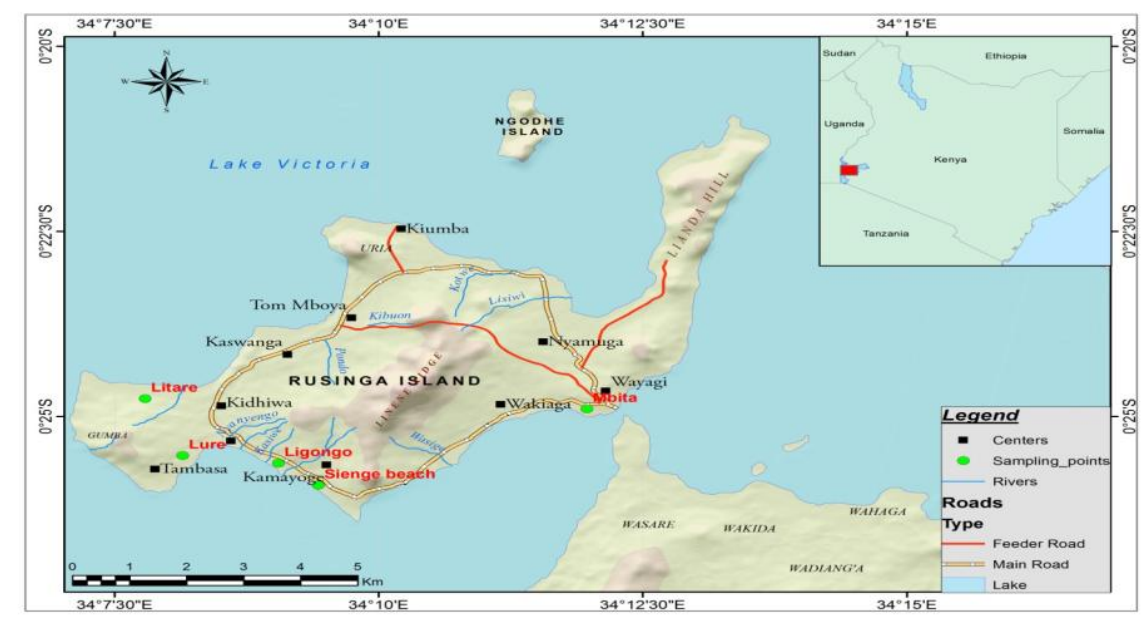

Figure 1: Map of Rusinga Island Showing Sampling Sites 


\section{Materials and Chemicals}

Pesticide standard mixture of over $99 \%$ pure was used for identification and quantification of pesticide residues in the samples. Pesticide standards were obtained from Dr. Ehrenstorfer GmbH Company (Germany). Hexane, acetone, dichloromethane and isooctane solvents were obtained from Fisher Scientific (USA).Analytical grade anhydrous sodium sulphate, sodium chloride, aluminum oxide, sodium hydroxide, hydrochloric acid, copper and methanol were also obtained from Fisher Scientific (USA). General purpose solvents were triple distilled before use.

\section{Samples collection}

Water was sampled by grab method into $2.5 \mathrm{~L}$ amber glass bottles and $1 \mathrm{ml}$ of $10 \mathrm{ppm}$ mercuric chloride added to kill microorganisms that could degrade the pesticides. The water samples were then temporarily stored in cool box containing wet ice, transported to the laboratory and kept in fridge at $4^{\circ} \mathrm{C}$ prior to extraction.

Sediments samples were collected from the same sites, where water was collected, by scooping with a pre-cleaned stainless steel shovel. Sediment was collected from three to five locations around the sites and mixed on clean piece of aluminum foil. Three composite of approximately $500 \mathrm{~g}$ were drawn and wrapped in a clean piece of aluminum foil, and packed in ziplock plastic bags. The samples were temporarily stored in the cool boxes containing wet ice and transported to the laboratory where they were stored in a deep freezer at -20 ${ }^{\circ} \mathrm{C}$ prior to extraction.

\section{Samples Extraction and Clean-Up}

Solvent-solvent extraction method was used in extraction of water samples. 2.0 litres of water was transferred into a separatory funnel. $50 \mathrm{ml}$ of $0.2 \mathrm{M}$ dipotasium hydrogen phosphate buffer was added to the sample, and $\mathrm{pH}$ adjusted to 7 by adding drops of $0.1 \mathrm{~N}$ sodium hydroxide and $0.1 \mathrm{M} \mathrm{HCl}$ solutions. The neutralized sample was treated with $100 \mathrm{~g}$ sodium chloride to salt out the pesticides from the aqueous phase. 60 $\mathrm{ml}$ triple distilled dichloromethane was added and shaken for two minutes while releasing pressure. The sample was allowed to settle for 30 minutes to enhance separation of the phases. The organic layer was collected in 250 $\mathrm{ml}$ Erlenmeyer flask and extraction repeated twice using $60 \mathrm{ml}$ portions of dichloromethane. The extract was stored stored at $4{ }^{\circ} \mathrm{C}$ in a refrigerator. The extracts were combined and cleaned by passing through $\mathrm{Al}_{2} \mathrm{O}_{3}$ chromatographic column topped with anhydrous sodium sulphate. Pesticide residues were sequentially eluted with $175 \mathrm{ml} \mathrm{n}$-hexane. The elutes was concentrated to $1 \mathrm{ml}$ using a rotary evaporator at $40^{\circ} \mathrm{C}$, and reconstituted in $0.5 \mathrm{ml}$ HPLC grade isooctane for GC analyses.

EPA method 3540 Soxhlet extraction of sediments was applied. The sediment samples were allowed to thaw for 4 hours in the laboratory prior to mixing. Triplicates of $20 \mathrm{~g}$ samples were dried overnight with activated anhydrous sodium sulphate $\left(\mathrm{Na}_{2} \mathrm{SO}_{4}\right)$ before transferring to the Soxhlet thimble. This sample was extracted with $200 \mathrm{ml}$ of hexane: acetone $(3: 1 \mathrm{v} / \mathrm{v})$ in a $250 \mathrm{ml}$ round bottomed flasks for at least 16 hours. The extracts were then stored at $4{ }^{\circ} \mathrm{C}$ in a refrigerator prior to sample cleanup. Cleanup was accomplished by eluting through $\mathrm{Al}_{2} \mathrm{O}_{3}$ topped with anhydrous sodium sulphate. The elute was concentrated to $1 \mathrm{ml}$ using a rotary evaporator at $40^{\circ} \mathrm{C}$, and reconstituted in $0.5 \mathrm{ml} \mathrm{HPLC}$ grade Isooctane for GC analyses.

\section{Quantification and Analysis of the Samples}

Analysis of OC Pesticides residue in water and sediment samples was carried out using Agilent 6890N gas chromatograph (equipped with an auto sampler (Agilent 7683 Series injector) and a micro-electron capture detector $(\mu \mathrm{ECD})$. The Injector and detector temperatures were maintained at $250{ }^{\circ} \mathrm{C}$ and $300{ }^{\circ} \mathrm{C}$, respectively. Helium gas was used as the carrier gas and nitrogen as make-up gas with a constant flow rate of $1 \mathrm{ml} / \mathrm{min}$. The injection volume was $1 \mu \mathrm{l}$ with a pulsed splitless injection mode. The following injection temperature program was applied: $90^{\circ} \mathrm{C}$ ( $3 \mathrm{~min}$ ), $90^{\circ} \mathrm{C}$ to $200{ }^{\circ} \mathrm{C}$ (at $30{ }^{\circ} \mathrm{C} / \mathrm{min}$ and hold time of $15 \mathrm{~min}$ ), $200{ }^{\circ} \mathrm{C}$ to $275{ }^{\circ} \mathrm{C}$ (at 30 $\mathrm{C} / \mathrm{min}$ and hold time of $5 \mathrm{~min}$ ). The column used was HP capillary column with the following dimensions: 30 $\mathrm{m}$ long, internal diameter of $0.25 \mathrm{~mm}$ and film thickness of $0.25 \mu \mathrm{m}$ ). Data processing was done using Chemstation software version A. 09.03(1417).

Quality control and quality assurance procedures included replicate sampling, extraction and analysis for all samples. Extraction of the samples also incorporated studies of spiked samples to determine the recovery rate of the method used. This was accomplished by spiking 2 litres of distilled water (recovery test for water samples) and $20 \mathrm{~g}$ of unhydrous $\mathrm{Na}_{2} \mathrm{SO}_{4}$ (recovery test for sediment samples) with respective standards of pesticides mixture under investigation to a sample concentration of $0.1 \mu \mathrm{g} / \mathrm{l}$, and following the same extraction and analytical procedures as for the samples. Pure distilled water samples were also incorporated as blanks, and these together with external standards were used to determine the detection limit of each pesticide investigated. 
Organochlorine Pesticides Residues in Water and Sediment from Rusinga Island, Lake Victoria,..

Data Analysis

The data obtained was analyzed using Statistical Package for Social Science (SPSS) to establish relationship between pesticide residue levels in the samples from different sampling sites and the seasonal variability. Bivariate correlation coefficients were established using Pearson product moment correlation coefficient, " $r$ ", which is a dimensionless index, whose value is in the range $-1.0 \leq \mathrm{r} \leq 1.0$.

\section{Results and Discussion}

High recoveries were obtained ranging from $72.58 \%$ to $94.84 \%$. Therefore, no corrections for recoveries were effected since they were within the acceptable range of 70-120\% [25]. Table 1 shows the results of recoveries obtained for individual pesticides.

Table 1: Percent recoveries of Pesiticides and Limits of Detection (LOD)

\begin{tabular}{|l|l|l|l|l|l|}
\hline Pesticide & Recovery $(\% \pm$ S.D) & LOD $(\mathbf{n g} / \mathbf{L})$ & Pesticide & Recovery $(\% \pm$ S.D) & LOD $(\mathbf{n g} / \mathbf{L})$ \\
\hline$\alpha$ HCH & $94.82 \pm 1.31$ & 1.1 & Endosulfan sulfate & $78.25 \pm 1.56$ & 2.1 \\
\hline$\beta$ HCH & $87.52 \pm 4.09$ & 1.6 & Aldrin & $94.26 \pm 5.23$ & 3.6 \\
\hline$\gamma$ HCH & $92.06 \pm 4.58$ & 1.6 & Dieldrin & $74.83 \pm 3.33$ & 3.1 \\
\hline$\delta$ - HCH & $82.54 \pm 6.95$ & - & Endrin & $80.01 \pm 4.21$ & 2.2 \\
\hline$p, p^{\prime}-$ DDT & $79.89 \pm 3.41$ & 1.7 & Endrin aldehyde & $77.81 \pm 3.63$ & 2.2 \\
\hline$p, p '-$ DDE & $78.35 \pm 5.12$ & 1.8 & Heptachlor & $92.08 \pm 4.56$ & 1.1 \\
\hline$p, p$ '- DDD & $79.31 \pm 2.84$ & 1.6 & Heptachlor epoxide & $88.35 \pm 2.45$ & 1.1 \\
\hline$\alpha$ - endosulfan & $72.58 \pm 4.95$ & 1.1 & Methoxychlor & $88.23 \pm 6.86$ & 1.6 \\
\hline$\beta$ - endosulfan & $93.23 \pm 7.13$ & 1.5 & & & \\
\end{tabular}

\section{Organochlorine Pesticides in Water}

Organochlorine pesticide detected in water during the month of September (short dry season) ranged between BDL to $0.830 \pm 0.02 \mu \mathrm{g} / \mathrm{L}$. DDT was the highest detected at Mbita Iceplant (Figure 2), while during the month of March (Long dry season) the concentration ranged between BDL to $9.835 \pm 1.2 \mu \mathrm{g} / \mathrm{L}$. $\beta$ - HCH was the highest detected at Sienge Beach point (Figure 3). Organochlorine residues detected in water samples during the month of December (Short rain season) ranged between below detection limit (BDL) to 0.055 $\pm 0.00 \mu \mathrm{g} / \mathrm{L}$. Endrin aldehyde was the highest detected at Sienge beach (Figure 4) and during the month of May (Long rain season) the concentration ranged between below detection limit (BDL) to $15.528 \pm 0.2 \mu \mathrm{g} / \mathrm{L}$. The residue level of alpha-HCH was the highest at Lure point (Figure 5).

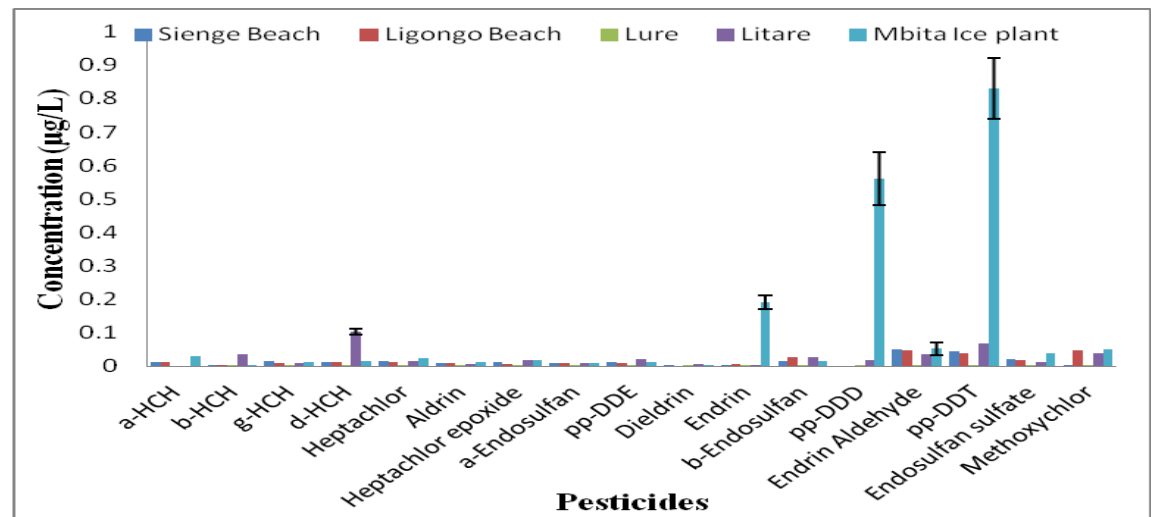

Figure 2: Organochlorine pesticide residues in water during short dry season $(\mu \mathrm{g} / \mathrm{l})$

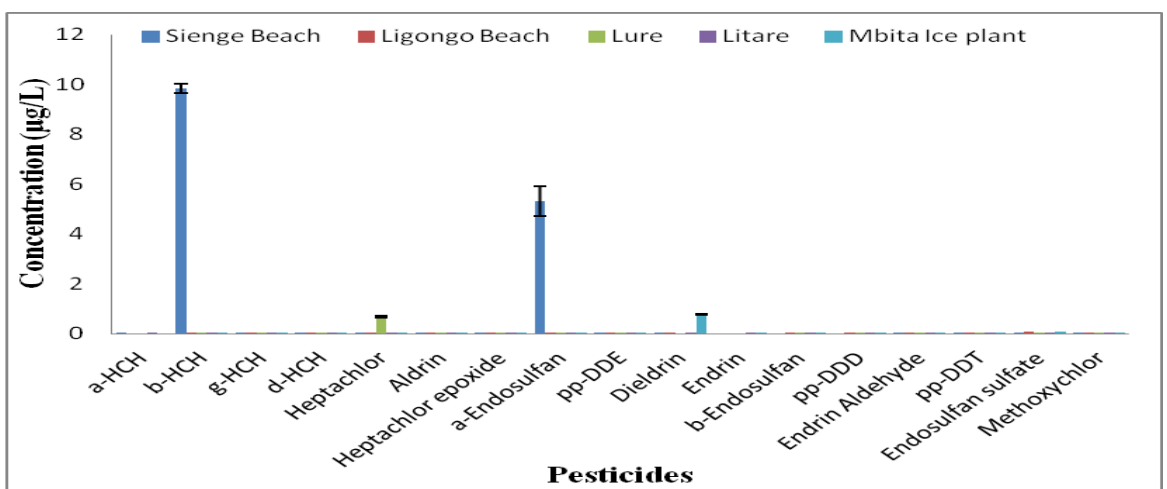

Figure 3: Organochlorine pesticide residues in water during long dry season $(\mu \mathrm{g} / \mathrm{l})$ 


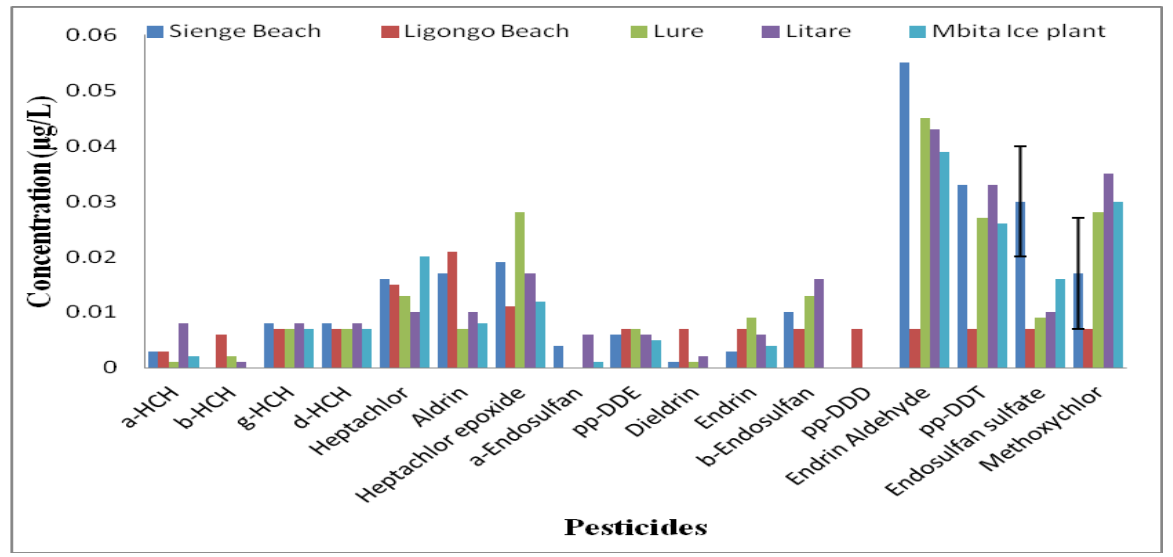

Figure 4: Organochlorine pesticide residues in water during Short Rain season $(\mu \mathrm{g} / \mathrm{l})$

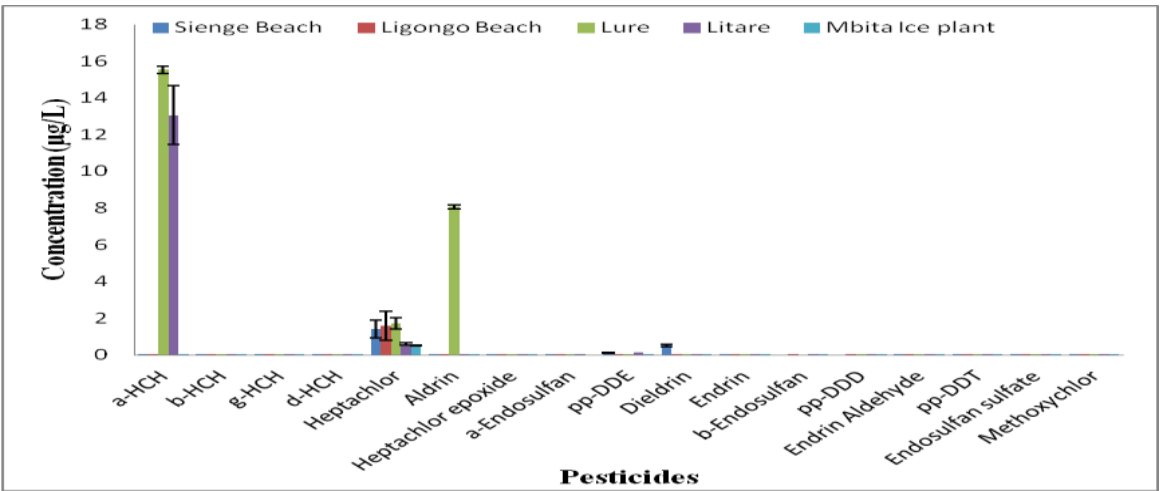

Figure 5: Organochlorine pesticide residues in water during Long Rain season $(\mu \mathrm{g} / \mathrm{l})$

Analysis of seasonal variations of the residue levels across the four seasons indicated that samples collected during the long rain season contained the highest amount of pesticide residues while the short dry seasons had lowest concentrations. The high levels of residues detected during the long rain season compared to the dry season were attributed to the runoff from the farms where the pesticides were previously applied (Figure $6)$.

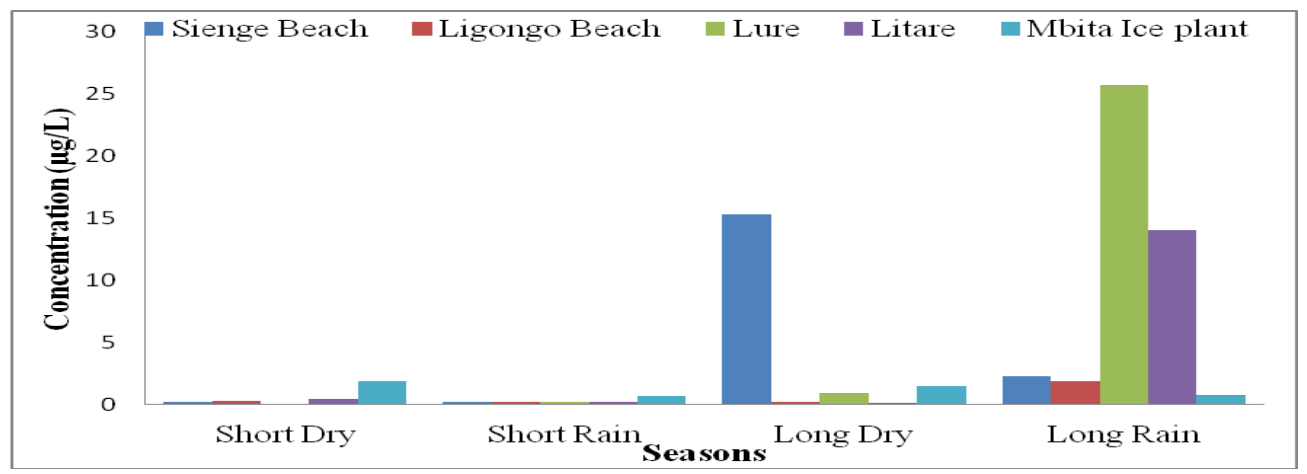

Figure 6: Seasonal Variation of Pesticides

\section{Organochlorine Pesticides in Sediment}

Organochlorine pesticide detected in sediment during the month of September (short dry season) ranged between BDL to $32.91 \pm 3.84 \mu \mathrm{g} / \mathrm{kg}$. a- $\mathrm{HCH}$ was the highest detected at Mbita iceplant (Figure 7), while during the month of March (Long dry season) the concentration ranged between BDL) to $19.12 \pm 2.54 \mu \mathrm{g} / \mathrm{Kg}$. Adrin had the highest detected level at Litare site (Figure 8). Organochlorine residues detected in water samples during the month of December (Short rain season) ranged between below detection limit (BDL) to $14.822 \pm$ $0.84 \mu \mathrm{g} / \mathrm{Kg}$. b- Endosulfan was the highest detected at Mbita Iceplant site (Figure 9) and during the month of May (Long rain season) the concentration ranged between below detection limit (BDL) to $24.835 \pm 2.65 \mu \mathrm{g} / \mathrm{Kg}$. ß-Endosulfan had the highest detected residue levels was at Lure site (Figure 10). 


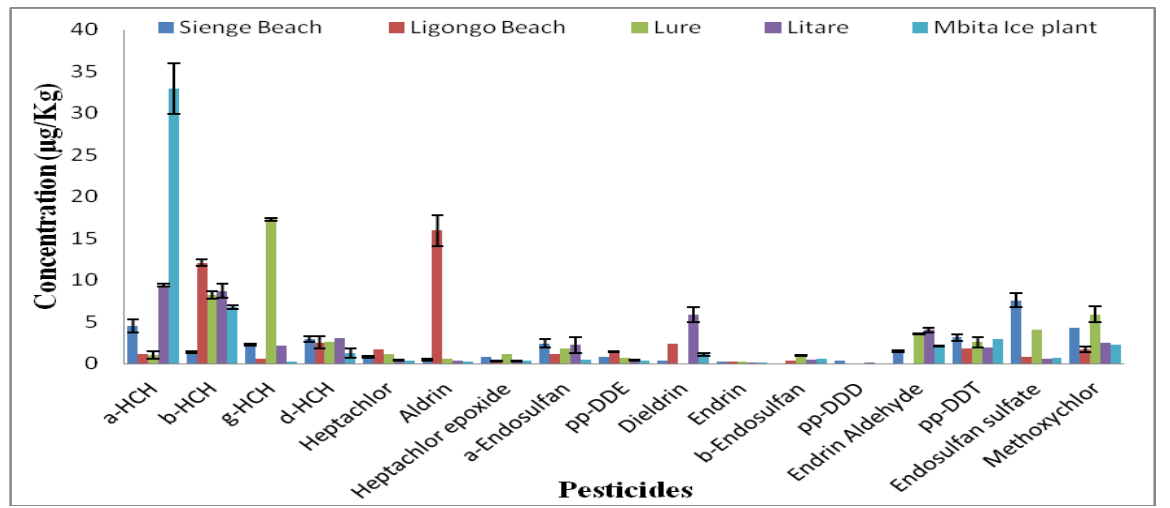

Figure 7: Organochlorine pesticide residues in Sediment during Short Dry season $(\mu \mathrm{g} / \mathrm{Kg})$

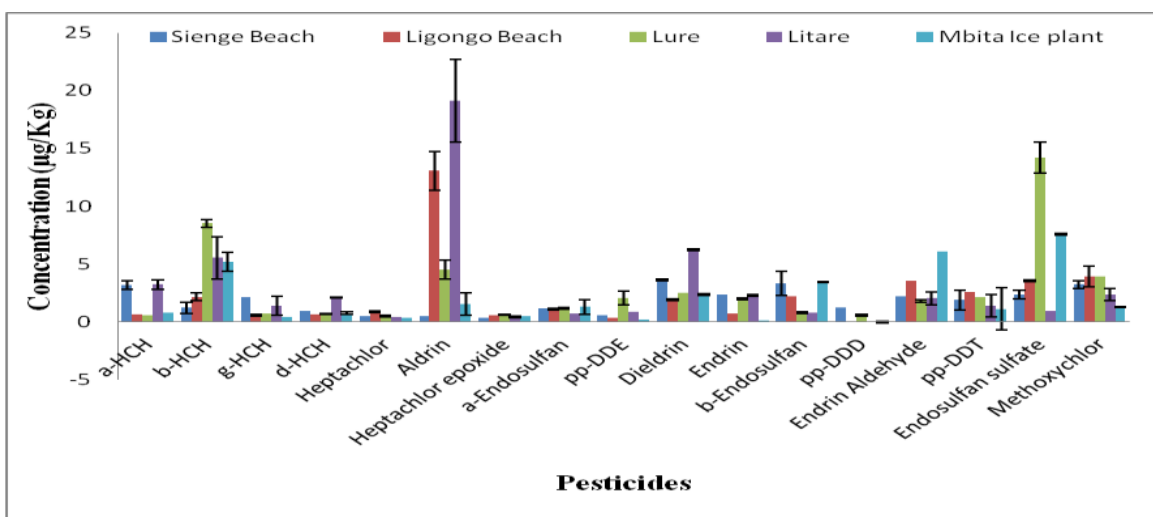

Figure 8: Organochlorine pesticide residues in Sediment during Long Dry season $(\mu \mathrm{g} / \mathrm{Kg})$

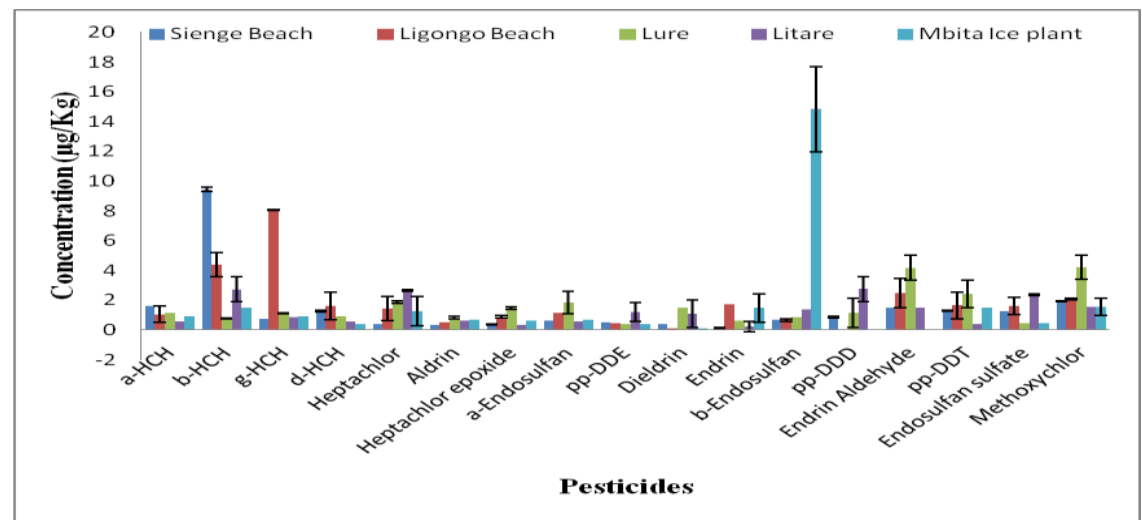

Figure 9: Organochlorine pesticide residues in Sediment during Short Rain season $(\mu \mathrm{g} / \mathrm{Kg})$

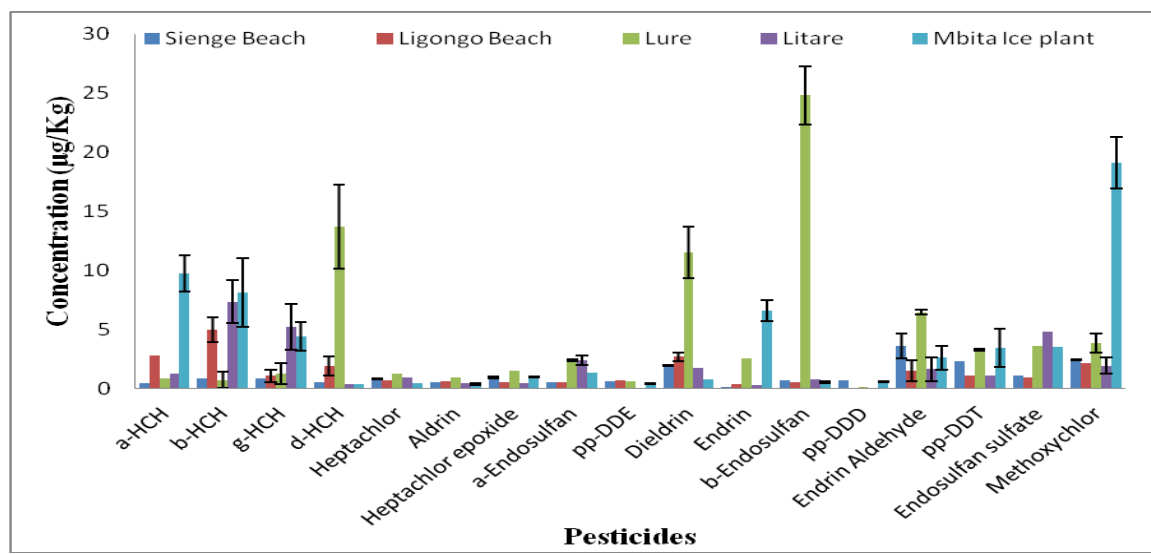

Figure 10: Organochlorine pesticide residues in Sediment during Long Rain season $(\mu \mathrm{g} / \mathrm{Kg})$ 
Analysis of seasonal variations of the residue levels in sediment across the four seasons indicated that samples collected during the long rain season contained the highest amount of pesticide residues while the short rain seasons had lowest concentrations. The high levels of residues detected during the long rain season compared to the dry season were attributed to the runoff from the fields where those compounds were previously applied (Figure 11).

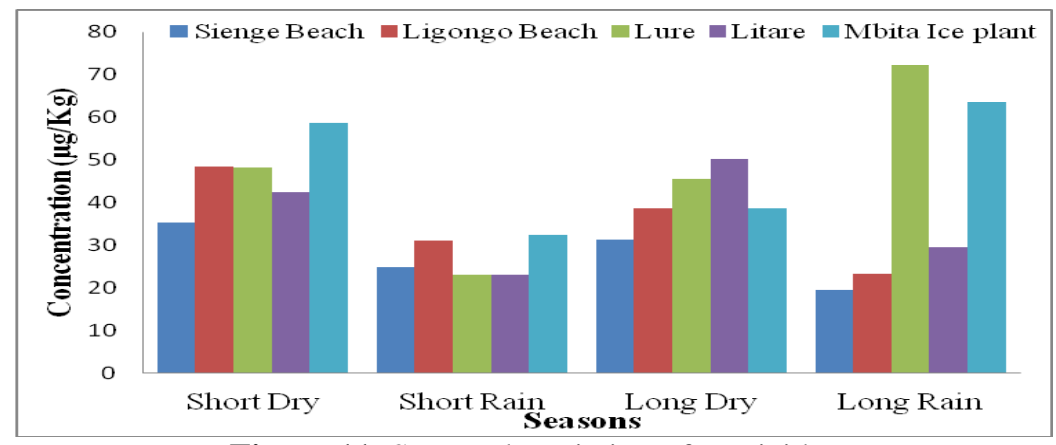

Figure 11: Seasonal Variation of Pesticides

\section{Discussion}

Organochlorine pesticide residues comprising of $p, p^{\prime}-\mathrm{DDT}, p, p^{\prime}$-DDE, $p, p^{\prime}-\mathrm{DDD}$, aldrin, dieldrin, $\alpha$ endosulphan, $\beta$-endosulphan, $\alpha-\mathrm{HCH}, \beta-\mathrm{HCH}, \gamma-\mathrm{HCH}, \delta-\mathrm{HCH}$, heptachlor, heptachlor epoxide, methoxychlor, diedrin, endosulfan sulfate and endrin were detected at varying frequencies and concentrations in water samples from lake Victoria.

In general the total concentration of $\alpha-\mathrm{HCH}, \beta-\mathrm{HCH}, \gamma-\mathrm{HCH}, \delta-\mathrm{HCH}$, methoxychlor, $p$ ' $p$ '-DDT, DDE and $p$ ' $p$ '-DDD were below the WHO guidelines for drinking water [26], whereas aldrin, heptachlor, heptachlor epoxide and methoxychlor were above WHO guidelines for drinking water. $\alpha$-endosulphan, $\beta$-endosulphan were above Australia guideline for drinking water, whereas endrin aldehyde and endrin were above EPA guideline for drinking water [26]. $\alpha-\mathrm{HCH}$ with total concentration of $7.023 \pm 0.01 \mu \mathrm{g} / \mathrm{L}$ and $22.624 \pm 3.23 \mu \mathrm{g} / \mathrm{Kg}$ water and sediment respectively recorded the highest followed by $\beta-\mathrm{HCH}$ with concentration of $2.96 \pm 0.97 \mu \mathrm{g} / \mathrm{L}$ and $21.94 \pm 4.21 \mu \mathrm{g} / \mathrm{Kg}$ water and sediment respectively while $\gamma-\mathrm{HCH}$ had the least concentration of $0.52 \pm 0.01 \mu \mathrm{g} / \mathrm{L}$ and $6.23 \pm 1.95 \mu \mathrm{g} / \mathrm{Kg}$ water and sediment respectively. The presence of isomeric residues of $\mathrm{HCH}$ and endosulfan in the samples suggested the use of technical products in the region. The higher residues of $\alpha-\mathrm{HCH}$ isomers compared to $\beta-\mathrm{HCH}$ could be attributed to degradation of $\gamma-\mathrm{HCH}$ and the use of technical $\mathrm{CH}$.

The main sources of organochlorine pesticide residues in Lake Victoria region are farming and aerial sprays in public health vector control. DDT and aldrin was mainly used in aerial sprays to kill mosquitoes to manage malaria [27]. Dieldrin and aldrin have been used for a long time to control termite in construction industry [22]. Lindane has been in use for seed dressing, whereas endosulfan, heptachlor, endrin and methoxychlor were used as insecticides [28]. The public use of these pesticides was restricted or banned in Kenya. High residues of methoxychlor, endosulfun, DDT, lindane and heptachlor in the environment indicate that some farmers are still using these pesticides.

Studies conducted by Wandiga et al., (2002) reported slightly lower frequency of most pesticides residues in marine samples from Kenya coast studies compared to those observed in this study. They reported residues of lindane, aldrin, $p, p^{\prime}$-DDT and $p, p$ '-DDE in most of the samples, whereas endosulfan, dieldrin, $p, p$ 'DDT and endrin were either present in low concentration or absent in most samples [29]. Study conducted on the Pesticide residues in Kenyan rivers and lakes have reported high level of $\alpha-\mathrm{HCH}, \beta-\mathrm{HCH}$, lindane, endosulfan, heptachlor, aldrin, heptachlor epoxide, dieldrin, endrin and methoxychlor in soil and water from the sugar belt zone of lake Victoria basin [27, 22]

In comparison to studies carried out in other countries, Mwevura et al., (2002) reported few

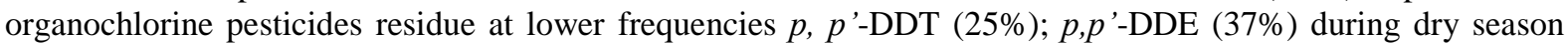
and high frequencies during wet season giving frequencies of $p, p$ '-DDT (81\%) $p, p^{\prime}$-DDE (100\%), dieidrin $(100 \%)$ and $\gamma-\mathrm{HCH}(6 \%)$ in samples from the coast area of Dar es Salaam, Tanzania [30].

The present study indicates that the banned or restricted organochlorine pesticide compounds are still detected in Lake Victoria basin due to their persistence nature. This posse's immediate danger to human and animals due to the pesticides bioaccumulations in food chain. Therefore the Policy makers should put in place a regular environmental monitoring program and mitigation strategies of reducing the pollutants and hence manage the water quality status within the lake, Awareness campaigns should be conducted to educate the general public on the adverse environmental and human health impacts of these pesticides and there should be a follow up on the compounds banned or restricted to ensure that they are not illegally used. 


\section{References}

[1] Mosleh Y.Y, Ismail S. M. M, Ahmed M.T and Ahmed Y. M (2003). Comparative toxicity and biochemical responses of certain pesticides to the mature earthworm Aporrectodea caliginosa under laboratory conditions. Environmental Toxicology 18:338-346.

[2] Larson D. L, Mcdonald S, Fivizzani A, Newton W and Hamilton S (2005). Effect of pesticides on amphibians and reptiles. Journal of Experimental Zoology 7:39-47.

[3] Pest Control and Product Board PCPB, (2008). Annual Report, July 2007/June 2008, (C 2008 Pest Control Products Board

[4] UNEP (2013). United Nations Environment Programme. Report of the Persistent Organic Pollutants Review Committee on the work of its ninth meeting. 28 November 2013, Rome.

[5] Ritter L, Solomon K. R, Forget J, Stemeroff M and Leary C. O (1995). Persistent Organic Pollutants. An Assessment Report on: DDT, Aldrin, Dieldrin, Endrin, Chlordane, Heptachlor-Hexachlorobenzene, Mirex, Toxaphene, Polychlorinated Biphenyls, Dioxins, and Furans. ForThe International Programme on Chemical Safety (IPCS) within the framework of the Inter-Organization Programme for the Sound Management of Chemicals (IOMC).

[6] Wania F and Mackay D (1996). Tracking the distribution of persistent organic pollutants. ES and T 30 (a). Pp 258-262.

[7] Lake Victoria Environmental Management Project/Ministry of Agriculture, Livestock Development and Marketing; (LVEMP/MoALD\& M, (1999). Environmental, Technical Socio-Economic, Gender and Socio-Cultural issues in catchment conservation: Main Findings and Conclusions. Interim Report Diversified Management Dynamics Ltd. Nairobi, Kenya.

[8] Aryamanya-Mugisha H (1993). Pesticides and Environmental Degradation. Proceedings of Uganda National symposium on pesticide Information Network. (UNSPIN). APEMAF Publication No. 6: pp 1-2.

[9] Orgaram. D. A (1992). Mining Industry, hazardous materials and toxic chemicals. National Environmental Task Force No. 6: pp 71-83.

[10] Calamari D, Aketch M. O and Ochumber P. B. O (1995). Pollution of Winam Gulf, Lake Victoria, Kenya: A case study for preliminary risk assessment. Lakes \& Reservoirs: Research \& Management: 1: 89-106.

[11] Edwards C. A (1987). The environmental impacts of pesticides. Parasitis 86:309-329.

[12] World Wildlife Fund (1999). Hazards and exposure associated with DDT and synthetic pyrethroids used for vector control. World Wildlife Fund, Washington DC.

[13] [13] Garabrant D. H, Held J, Langgholz B, Peter J. M and Mark T. M (1992). DDT and related compounds and risk of pancreatic cancer. J Natl. cancer Inst. 84(10):764-771.

[14] [14] Edwards C. A (1987). The environmental impacts of pesticides. Parasitis 86:309-329.

[15] [15] Hassall A. K (1990). The Biochemistry and Uses of Pesticides - Structures Metabolism, Mode of Action and Use in Crop Protection. Macmillan press Ltd, London.

[16] [16] Swan S, Elkin E and Fenster L (2000). The question of declining sperm density revisited: An analysis of 101 studies published 1934-1996. Environmental Health Perspectives 108, 10, 961-966.

[17] Kishimba M. A, Henry L, Mwevula H, Mmochi A .J, Mihale M, and Hellar H (2004).The status of pesticide pollution in Tanzania. Talanta 64:48-53.

[18] FAO (2001). Baseline study on the problem of obsolete pesticides stocks. FAO pesticide disposal ser. No. 9. FAO, Rome.

[19] ] Kasozi N, Kiremire T, Bugenyi B, Kirsch H and Nkedi-Kizza P (2006). Organochlorine residues in fish and water samples from Lake Victoria, Published online on 1 March 2006.

[20] Madadi V. O (2005) Chemodynamic studies and assessment of pesticide residues in lake Victoria catchment area for rivers Sio and Nzoia, M.Sc. Thesis, University of Nairobi, Nairobi, Kenya.

[21] Abong'o D. A (2009). Occurrence, distribution and environmental impacts of organochlorine pesticide residues in the Lake Victoria catchment: A case study of River Nyando drainage basin of Winam Gulf, Kenya. PhD thesis, Department of Chemistry, University of Nairobi, Kenya.

[22] Getenga Z. M, Kengara F. O and Wandiga S. O (2004). Determination of organochlorine pesticides in soil and water from river Nyando Drainage System within Lake Victoria Basin, Kenya. Bull. Environ. Contam. Toxicol 72 (2): $335-342$.

[23] Muendo B. M, Lalah J. O and Getanga Z. M (2005). Behaviour of pesticides residues in agricultural soil and adjacent River Kuywa sediment and water samples from Nzoia sugarcane belt in Kenya. The Environmentalist Vol. 25 issue 1 March 2005.

[24] [24] Gikuma-Njuru P, Hecky R. E, Guildford S. J (2010). Surficial sediment phosphorus fractions along a biogeochemical gradient in Nyanza (Winam Gulf), northeastern Lake Victoria and their possible role in phosphorus recycling and internal loading. Biogeochemistry 97:247-261.

[25] Hill A (2000). Quality control procedures for pesticide residue guidline for residue monitoring in the European Union, Second Ed; Document no. SANCO/3103/2000, European Commission.

[26] IUPAC, (2003). Regulatory Limits For Pesticides Residues In Water. Pure appl. Chem. 75(8): 1125-1156.

[27] Mitema E. S and Gitau F. K (1990). Organochlorine residues in fish from Lake Victoria, Kenya. Afri J. Ecol. 28(3): 234-239

[28] Pest Control and Product Board (PCPB) (1992) Record on annual import statistics of various pesticides imported in Kenya, Government Press, Nairobi, Kenya.

[29] Wandiga S. O, Yugi P. O, Barasa M. W, Jumba I. O and Lalah J. O (2002). The Distribution of Organochlorine Pesticides in Marine Samples A long the Indian Ocean Coast of Kenya. Environmental Toxicology, 23: 1235-1246.

[30] Mwevura H, Othman O. C, and Mhehe G. L (2002). Organochlorine pesticide residues in water from the coastal area of Dar Es salaam and their effect on aquatic biota. Tanz. J. Sci. 28(2):117-130. 